\title{
UJI PERSAMAAN LANGMUIR DAN FREUNDLICH PADA PENYERAPAN Mn(II) OLEH KOMPOSIT $\mathrm{Fe}_{3} \mathrm{O}_{4}$-ZEOLIT
}

\author{
Mona Lisa, Poedji Loekitowati Hariani, M. Faizal
}

Program Studi Pengelolaan Lingkungan Pascasarjana Universitas Sriwijaya

\begin{abstract}
ABSTRAK
Penelitian ini bertujuan mengetahui metode adsorpsi yang sesuai untuk menentukan kapasitas serap maksimum $\mathrm{Mn}(\mathrm{II})$ oleh komposit $\mathrm{Fe}_{3} \mathrm{O}_{4}$-zeolit pada larutan uji menggunakan persamaan Langmuir dan Freundlich. Konsentrasi Mn(II) pada larutan dikur dengan alat Spektroskopi Serapan Atom (SSA). Hasil penelitian menunjukkan bahwa kondisi optimum untuk proses adsorpsi yaitu pada saat berat komposit $0.4 \mathrm{~g} \mathrm{Fe}_{3} \mathrm{O}_{4}$-zeolit dan lamanya waktu kontak 60 menit pada kecepatan pengadukan $100 \mathrm{rpm}$. Koofisien determinan $\left(R^{2}\right)$ untuk persamaan Langmuir yaitu 0.934 dan lebih besar dari $R^{2}$ dari persamaan Freundlich. Artinya penyerapan Mn(II) pada larutan oleh komposit $\mathrm{Fe}_{3} \mathrm{O}_{4}$-zeolit ditentukan dengan mengikuti persamaan Langmuir. Kapasitas penyarapan maksimum Mn(II) pada larutan uji yaitu sebesar 181,8 mg/g. Sehingga, komposit $\mathrm{Fe}_{3} \mathrm{O}_{4}$ zeolitdapat direkomendasikan untuk mengurangi Mn(II) pada air ataupun air limbah.
\end{abstract}

Kata kunci : Mn(II), adsorpsi, AAS, Langmuir, Freundlich

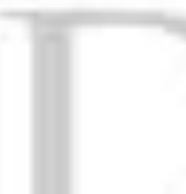

\section{ABSTRACT}

This research intends to know appropriate isotherm adsorption methode to determine maximum capacity of Composited of Zeolite with nano magnetic to Mn(II) in solution. Equation wich used are Langmuir and Freundlich isotherm adsorption equations. Concentration of Mn(II) in solution was determined by Atomic Absorption Spectroscopy (AAS). The experiment result showed that optimum condition for adsorption are in $0.4 \mathrm{~g}$ of composited of Zeolite-Fe3O4 weight and 60 minutes contact time and mixture at $100 \mathrm{rpm}$. Coefficient of determination $\left(R^{2}\right)$ from Langmuir isotherm was 0.934 and bigger then $R^{2}$ from Freundlich isotherm was 0.905 . It means adsorption of $\mathrm{Mn}(\mathrm{II})$ by composited of Zeolite-Fe3O4 insolution followed Langmuir isotherm. Maximum adsorption capacity of composited of Zeolite- $\mathrm{Fe}_{3} \mathrm{O}_{4}$ in solution was $182 \mathrm{mg} / \mathrm{g} \mathrm{Mn}(\mathrm{II})$. Thus, composited of Zeolite- Fe3O4 are recommended to reduce $\mathrm{Mn}(\mathrm{II})$ in water or waste water

Keywords: Mn(II), adsorption, SSA, Langmuir, Freundlich. 


\section{PENDAHULUAN}

Mangan (Mn) adalah salah satu logam yang banyak dijumpai di bumi dan umunya tidak ditemukan dalam bentuk senyawa murni, tapi berikatan dengan unsur lain dan bisa jugaterlarut dalam bentuk ion (ATSDR, 2000). Meskipun Mn dibutuhkan tubuh membantu fungsi enzim pada sel tubuh, namun jumlah yang berlebih dapat menimbulkan masalah kesehatan seperti peningkatan berat badan, mempengaruhi neurotransmisi ke otak, lebih lanjut dapat menyebabkan hiperplapsia dan hiperkeraton (WHO, 2011). Kadar Mn yang dapat ditoleransi tubuh manusia yaitu $0.06 \mathrm{mg} / \mathrm{kg}$ berat badan, dengan asumsi kebutuhan air manusia adalah 2 liter per hari.

Jumlah Mn yang disyaratkan terkandung dalam air dan air limbah diatur dengan menggunakan instrumen Baku Mutu Lingkungan.Guna memenuhi persyaratan tersebut dibutuhkan suatu pengolahan untuk menurunkan jumlah Mn dalam air.Salah satu pengolahan yang dapat dilakukan yaitu dengan metode adsorpsi. Adsorpsi adalah pengumpulan molekul padat pada suatu permukaan baik permukaan gas dengan cairan, permukaan cairan dengan cairan seperti diterjen dan padatan atau larutan pada permukaa keras/ padat yang berpori (M.D Levan et al, 2008). Zat atau bahan yang digunakan untuk adsorpsi disebut adsorben.

Salah satu adsorben yang sudah lama digunakan dalam pengolahan air yaitu zeolit. Zeolit adalah adsorben yang unik, karena 20-50\% bagiannya terdiri dari rongga kosong dan memiliki surface area yang besar sehingga sangat efektif dalam penyerapan (J. Dixon et al, 1989). Guna meningkatkan kapasitas adsorpsi zeolit alam, biasanya dilakukan treatment/perlaukan khusus seperti pemanasan, pencucian atau pelepasan senyawa pengotor dan zeolit juga dapat dikomposit dengan oksida besi.

Menurut Hariani et al (2014), modifikasi adsorban Zeolit menjadi semacam komposit dapat meningkatkan kemampuan adsorban dalam mengadsorpsi polutan. Penambahan atau penggabungan zeolit dengan oksida besi dapat menghasilkan zat baru yang mampu menyerap polutan dan sekaligus bersifat magnetik, sehingga pengumpulannya kembali setelah aktifitas penyerapan dapat dilakukan dengan cara magnetisasi (Y. Sarwanto et al, 2013)

\section{METODOLOGI PENELITIAN}

Pada penelitian ini dipelajari kemampuan adsorpsi $\mathrm{Mn}$ oleh komposit $\mathrm{Fe}_{3} \mathrm{O}_{4}$-zeolit, dengan variasi berat komposit dan lamanya waktu kontak, untuk kemudian didapat kondisi optimum penyerapannya.Setelah itu juga ditentukan juga kapasitas asorpsi maksimumnya dengan mengujinya dengan persamaan Langmuir atau Freundlich.

\section{Bahan dan Alat}

Bahan yang digunakan dalam penelitian ini yaitu zeolit, kertas saring, akuadest, $\mathrm{NaOH}$, $\mathrm{HCl}, \mathrm{H}_{2} \mathrm{O}_{2} 30 \%$, etanol, $\mathrm{FeCl}_{2}, \mathrm{FeCl}_{3}$, aseton, larutan standar $\mathrm{Fe} 1000 \mathrm{ppm}$ dan Larutan standar Mn 1000 ppm. Peralatan yang digunakan dalam penelitian ini adalah Atomic Absorption Spectrophometer, Circulating Aspirator AA 700, Shaker SA 400, Ayakan/ wire mesh/ siever, Furnace, timbangan, gelas ukur, pipet ukur, labu pengenceran, buret, erlenmeyer, kuvet, $\mathrm{pH}$ meter, Magnet Neodymium (dengan diameter $20 \mathrm{~mm}$ dan tebal $2 \mathrm{~mm}$ )

\section{Pembuatan komposit $\mathrm{Fe}_{3} \mathrm{O}_{4}$-zeolit}

Sebanyak 200 gram zeolit alam dihaluskan dan diayak dengan ukuran ayakan 200 mesh, selanjutnya zeolit halus dipanaskan pada temperatur $400^{\circ} \mathrm{C}$ di dalam furnace selama 5 jam.Komposit $\mathrm{Fe}_{3} \mathrm{O}_{4}$-zeolit (perbandingan $\mathrm{Fe}_{3} \mathrm{O}_{4}$ dan zeolit 1:1) disintesis dari reaksi 16,25 gram $\mathrm{FeCl}_{3}$, 6,35 gram $\mathrm{FeCl}_{2}$ dan 11,6 $\mathrm{g}$ zeolit dilarutkan dalam $200 \mathrm{~mL}$ akuades dan dipanaskan pada suhu $70^{\circ} \mathrm{C}$ selama 30 menit sambil ditambahkan $\mathrm{NaOH} 2 \mathrm{M}$ sedikit demi sedikit sampai $\mathrm{pH} \pm 10$, campuran diaduk dengan magnetik stirer. Komposit yang dihasilkan disaring dan dicuci sampai $\mathrm{pH}$ netral. Selanjutnya komposit dimasukan dalam oven dan dikeringkan pada suhu $110^{\circ} \mathrm{C}$ sampai berat konstan (Hariani et al, 2014) 


\section{Pembuatan Larutan Uji}

Pembuatan Larutan uji Mn dengan konsentrasi $10 \mathrm{ppm}$. Larutan standar 1000 ppm dimasukkan ke dalam 2 Labu ukur yang berukuruan 1 liter, masing-masing sebanyak $10 \mathrm{ml}$, kemudian ditambahkan larutan pengencer untuk masing-masing labu ukur itu sampai pada garis tera. Masingmasing larutan diambil $40 \mathrm{ml}$ dari setiap labu ukur dan diukur konsentrasi awal (sebelum perlakuan). Sisa larutan lain dimasukkan sebanyak $70 \mathrm{ml}$ kepada 25 erlemeyer.

\section{Penentuan Kondisi optimum}

Komposit $\mathrm{Fe}_{3} \mathrm{O}_{4}$-zeolit ditimbang $0.1 \mathrm{~g}, 0.2$ g, $0.3 \mathrm{~g}, 0.4 \mathrm{~g}$ dan $0.5 \mathrm{~g}$, masing masing 5 komposit kemudian dimasukkan ke dalam erlemeyer. Untuk waktu kontak 0 menit, diaduk secara manual kurang dari satu menit kemudian didiamkan selama 5 menit. Setelah itu dilakukan pemisahan komposit dengan cara magnet ditempelkan ke bagian luar erlemeyer dan larutan dituang ke gelas piala. Kemudian diukur konsentrasi akhirnya.

Hal yang sama juga dilakukan kepada larutan lainnya, namun dilakukan pengadukan dengan waktu kontak 15, 30, 45 dan 60 menit dengan kecepatan $100 \mathrm{rpm}$. Setelah pengadukan dilakukan pemisahan komposit dengan cara magnetisasi. Kemudian diukur kandungan Mn yang tersisa pada larutan.

Besarnya $\%$ penyerapan dihitung dengan rumus:

Konsentrasi Mn akhir - Konsentrasi awal Kosentrasi awal $x 100 \%$

Kemudian dibuat grafik penyerapan dibanding dengan berat komposit untuk tiap tiap waktu kontak.Dari grafik tersebut ditentukan berat dan waktu yang menunjukkan penyerapan tertinggi dan dicatat sebagi waktu $\mathrm{T}$ dan berat $\mathrm{M}$. yang digunakan sebagai dasar penelitian berikutnya.

\section{Uji persamaan Langmuir dan Freundlich}

Komposit $\mathrm{Fe}_{3} \mathrm{O}_{4}$-zeolit ditimbang seberat $\mathrm{M}$ (dari tahapan sebelumnya) ditambahkan kepada larutan Mn dengan konstrasi $5 \mathrm{ppm}$, 10 ppm, 15 ppm, 20 ppm, 25 ppm dan 30 ppm (dicatat sebagi $\mathrm{C}_{\mathrm{o}}$ ). kemudian dilakukan pengadukan dengan shaker selama waktu $\mathrm{T}$. Setelah itu komposit dipisahkan dari larutan dengan cara megnetik. Konsentrasi setelah perlakuan akan diukur sebagai $\mathrm{C}_{\mathrm{e}}$.

$\mathrm{C}_{\mathrm{o}}$ atau $\mathrm{M}$ dan $\mathrm{C}_{\mathrm{e}}$ digunakan untuk perhitungan pada persamaan (W.W Nazaroff et al, 2001)

$a_{0}=\frac{x}{m}=\frac{M-\left(C_{0} V_{0}\right)}{m}$

Persamaan Adsorpsi Langmuir (T.D

Reynold, 1982) :

$\frac{x}{m}=\frac{Q o b C_{E}}{1+b C_{E}}$

Bentuk persamaan (2), dapat dirubah menjadi persamaan (3) berikut:

$\frac{\mathrm{Ce}}{\mathrm{qe}}=\frac{1}{\mathrm{Qab}}+\frac{\mathrm{Ce}}{\mathrm{Qo}}$

Dengan $\mathrm{C}_{\mathrm{e}}$ adalah konsentrasi zat adsorbat pada kesetimbangan (mg. L-1) Qo adalah kapasitas adsorpsi maksimum (mg g-1)

Dengan membuat kurva $\mathrm{C}_{\mathrm{e}} / \mathrm{q}_{\mathrm{e}}$ terhadap $\mathrm{C}_{\mathrm{e}}$ akan diperoleh persamaan linear dengan intersep 1/Qo sehingga nilai $Q_{o}$ dan konstanta untuk $b$ dapat dihitung.

Persamaan Adsorpsi Freundlich (W.W

Nazaroff et al, 2001)

$q_{e}=\frac{x}{m}=K_{f} C_{e}^{1 / n}$

Atau dalam bentuk log nya persamaan (4)

berubah menjadi bentuk persamaan (3)

berikut ini

$\log _{10}\left(a_{\theta}\right)=\frac{1}{n} \log _{10}\left(C_{\theta}\right)+\log _{10} K_{f}$

Dengan data yang ada, dibuat grafik $\log \mathrm{C}_{\mathrm{e}}$ terhadap $\log \mathrm{q}_{\mathrm{e}}$ akan didapat $\log \mathrm{K}_{\mathrm{f}}$ sebagai besarnya intersep, sehingga nilai $\mathrm{n}$ dan $\mathrm{K}_{\mathrm{f}}$ dapat diketahui.

\section{HASIL DAN PEMBAHASAN}

\section{Berat Komposit dan Waktu Kontak Optimum}

Setelah dilakukan perhitungan \% penyerapan $\mathrm{Mn}$ dengan variasi berat 
komposit dan lamanya waktu kontak, didapat hasil sebagaimana Tabel 1.

Tabel 1. Persentase Penyerapan Mn pada larutan Uji 10 ppm

\begin{tabular}{cccccc}
\hline \multirow{2}{*}{$\begin{array}{c}\text { Waktu } \\
\text { (menit) }\end{array}$} & \multicolumn{5}{c}{ Berat Komposit (g) } \\
\cline { 2 - 6 } & 0.1 & 0.2 & 0.3 & 0.4 & 0.5 \\
\cline { 2 - 6 } & 1.36 & 3.53 & 10.94 & 12.12 & 12.89 \\
\hline 0 & 1.24 & 12.06 & 22.74 & 32.88 & 34.85 \\
15 & 16.30 & 36.91 & 57.17 & 77.53 & 89.83 \\
30 & 39.84 & 52.98 & 83.14 & 94.30 & 98.72 \\
45 & 49.76 & 75.61 & 98.90 & 99.81 & 99.81 \\
60 & & & & & \\
\hline
\end{tabular}

yang cukup diperlukan untuk mencapai kesetimbangan adsorpsi.Jika fase cair yang berisi adsorben dalam keadaan diam, maka difusiadsorbat melalui permukaan adsorben akan lambat. Maka diperlukanpengadukan untuk mempercepat adsorpsi (C.N Sawyer, 1987).

Penentuan berat optimum komposit dalam menyerap Mn paling banyak dilakukan dengan membandingkan persentase penyerapan tiap berat komposit.Dapat dilihat pada grafik penyerapan Gambar 2.

Tabel 1 adalah tabel persentase penyerapan berdasarkan lamanya waktu kontak dan variasi berat komposit. Pada tabel tersebut terlihat bahwa persentase penyerapan tertinggi yang dapat dicapai, juga meningkat seiring bertambahnya waktu dan berat komposit sebgai adsorben.Pada waktu kontak 15 menit penyerapan tertingginyalebih dari $34 \%$, pada waktu kontak 30 menit penyerapan tertingginya lebih dari $89 \%$, pada waktu kontak 45 menit penyerapan tertinggi lebih dari $98 \%$ dan pada waktu kontak 60 menit penyerapan mencapai 99,81\%.

Pengaruh pengadukan terlihat pada waktu kontak 0 atau waktu kontak tanpa pengadukan, sebagaimana terlihat pada Gambar 1.

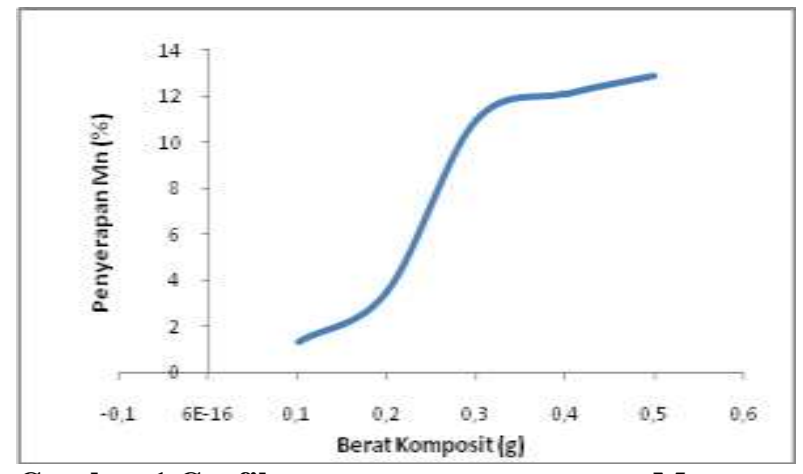

Gambar 1.Grafik persentase penyerapan Mn terhadap berat komposit pada waktu kontak pengadukan 0

Pada Gambar 1. Terlihat bahwa penyerapan Mn tidak mencapai $14 \%$ jika tanpa pengadukan dan dengan waktu kontak hanya 5 menit.Hal ini juga membuktikan pendapat Sawyer dan McCartybahwa faktor-faktor yang mempengaruhi adsorpsi diantaranya yaitu waktu dan pengadukan, waktu kontak
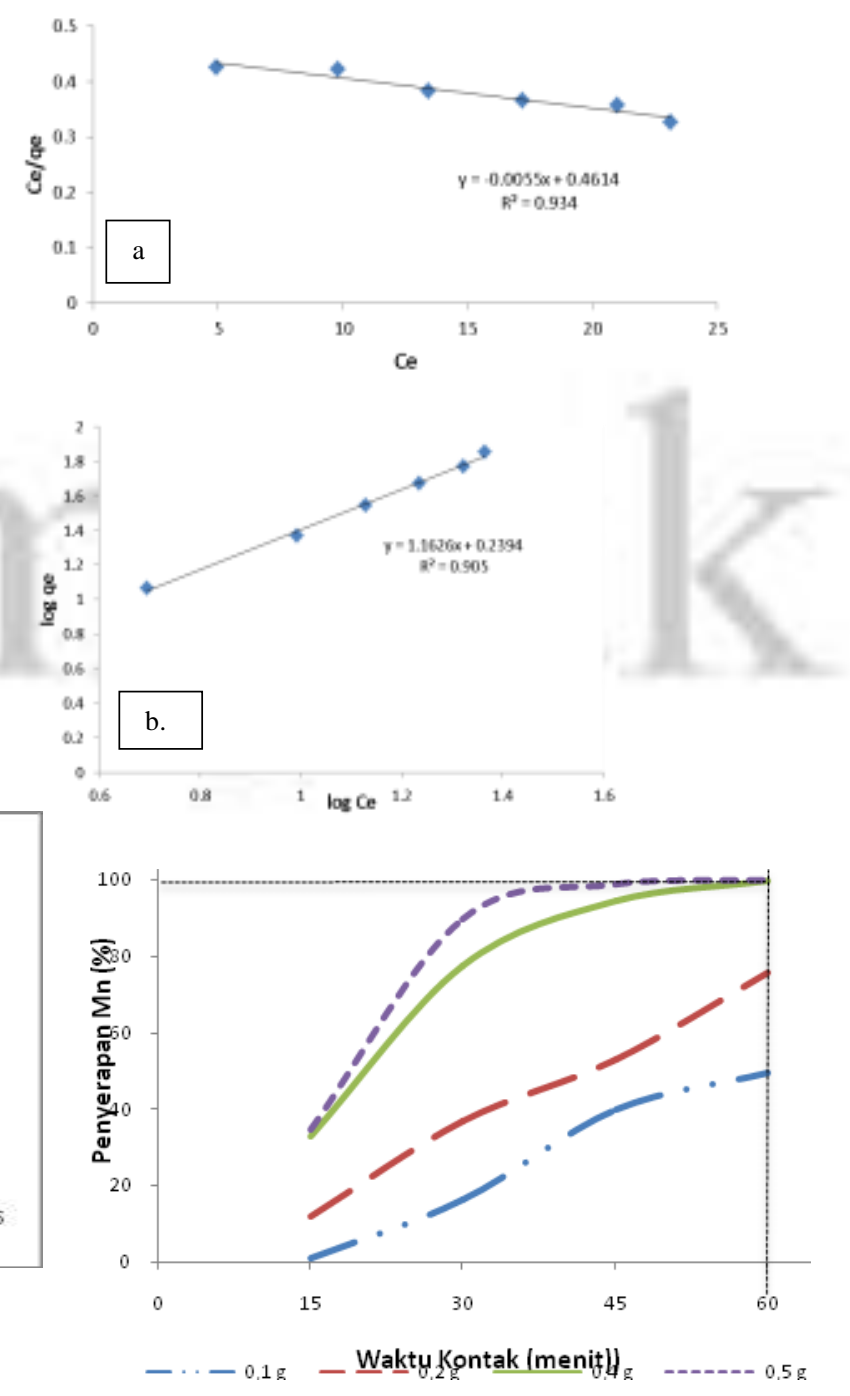

\section{Gambar 2. Persentase penyerapan Mn(II) berdasarkan waktu kontak dan berat komposit}

Penyerapan tertinggi pada waktu kontak 60 menit mencapai $99,81 \%$ yaitu pada berat komposit $0.4 \mathrm{~g}$ dan $0.5 \mathrm{~g}$, sehingga waktu 
optimum yaitu 60 menit dan berat komposit 0.4 g. Pemilihan ini didasarkan atas pertimbangan, bahwa meskipun berat komposit dinaikkan menjadi 0,5 pertambahan penyerapan tidak lagi signifikan naiknya.

Pengujian persamaan Langmuir dan Freundlich dilakukan untuk mengetahui kapasitas maksimum penyerapan $\mathrm{Mn}$ (II) oleh komposit $\mathrm{Fe}_{3} \mathrm{O}_{4}$-zeolit. $\mathrm{C}_{\mathrm{o}}$ adalah kosentrasi awal larutan $\mathrm{Mn}, \mathrm{C}_{\mathrm{e}}$ adalah konsentrasi akhir setelah diaduk selama waktu optimal yaitu 60 menit dan berat komposit yang digunakan yaiti $0,4 \mathrm{~g}$ pada kecepatan aduk $100 \mathrm{rpm}$. Perhitungan untuk membuat grafik linear persamaan Langmuir dan Freundlich sebagaimana Tabel 2.

Tabel 2. Perhitungan untuk Persamaan Langmuir dan Freundlich

\begin{tabular}{rrrrrr}
\hline $\mathrm{C}_{\mathrm{o}}$ & $\mathrm{C}_{\mathrm{e}}$ & $\mathrm{q}_{\mathrm{e}}$ & $\mathrm{C}_{\mathrm{e}} / \mathrm{q}_{\mathrm{e}}$ & $\log \mathrm{C}_{\mathrm{e}}$ & $\log \mathrm{q}_{\mathrm{e}}$ \\
\hline 5 & 4.959 & 11.632 & 48.380 & 0.695 & -0.989 \\
10 & 9.826 & 23.280 & 22.589 & 0.992 & -0.362 \\
15 & 13.439 & 35.148 & 3.444 & 1.128 & 0.591 \\
20 & 17.210 & 46.988 & 2.467 & 1.236 & 0.844 \\
25 & 21.014 & 58.823 & 2.109 & 1.323 & 0.998 \\
30 & 23.129 & 70.952 & 1.346 & 1.364 & 1.235 \\
\hline
\end{tabular}

Dari Tabel 2. Dilakukan plotting data untuk kemudian dilakukan pembuatan grafik regersinya.

Pengujian persamaan adsorpsi Langmuir dan Freundlich ditujukan untuk menentukan diantara kedua persamaan tersebut yang memperlihatkan hubungan yang erat antar komponen pembentuk persamaannya.Hal ini dibuktikan dengan nilai $\mathrm{R}^{2}$ lebih dari dari 0,9 dan yang paling tinggi diantara keduanya. Untuk lebih jelasnya perbandingan hasil perhitungan atas kedua persamaan tersebut dapat dilihat pada Tabel 3.
Tabel 3. Perbandingan Persamaan Langmuir dan Persamaan Freundlich untuk Penyerapan Mn pada larutan uji

\begin{tabular}{|c|c|c|}
\hline & $\begin{array}{l}\text { Persamaan } \\
\text { Freundlich }\end{array}$ & $\begin{array}{c}\text { Persamaan } \\
\text { Langmuir }\end{array}$ \\
\hline $\begin{array}{c}\text { Bentuk } \\
\text { Persamaan garis } \\
\text { lurus }\end{array}$ & $\begin{array}{c}\mathrm{y}=1.1626 \mathrm{x}+ \\
0.2394\end{array}$ & $\begin{aligned} y= & -0.0055 x+ \\
& 0.4614\end{aligned}$ \\
\hline$\overline{\mathrm{R}^{2}}$ & $\mathrm{R}^{2}=0.905$ & 0.934 \\
\hline Konstanta & $\begin{array}{l}\mathrm{Kf}=1,735 \\
\mathrm{n}=0.860\end{array}$ & $\begin{array}{c}\mathrm{Q}_{\mathrm{o}}=181,8 \mathrm{mg} / \mathrm{g} \\
\mathrm{b}=0.012\end{array}$ \\
\hline $\begin{array}{c}\text { Bentuk } \\
\text { persamaan }\end{array}$ & $\frac{x}{m}=1,735 C_{c}^{1 / 2,700}$ & $\frac{x}{m}=\frac{2.184 C_{s}}{1+0.012 C_{z}}$ \\
\hline
\end{tabular}

Pada Tabel 3, terlihat bahwa $\mathrm{R}^{2}$ pada persamaan Langmuir lebih besar dari $\mathrm{R}^{2}$ persamaan Freundlich, sehingga sifat adsorpsi oleh komposit ini mengikuti persamaan Langmuir. Kemampuan adsorpsi maksimum oleh komposit $\mathrm{Fe}_{3} \mathrm{O}_{4}$-zeolitpada persamaan Langmuir ditunjukkan dengan nilai $Q_{o}$ yaitu sebesar $181,8 \mathrm{mg} / \mathrm{g}$, ini artinya setiap $1 \mathrm{~g}$ komposit $\mathrm{Fe}_{3} \mathrm{O}_{4}$-zeolitdapat menyerap 181,8 mg Mn dalam larutan.

Hubungan antara jumlah adsorbat yang terserap dengan konsentrasi adsorbat dalam larutan pada keadaan kesetimbangan dan suhu tetap yang dinyatakan dengan isoterm adsorpsi Langmuir maka penyerapan hanya terjadi pada satu lapisan saja monolayer (B. Al-Duri, 1995).

Pemanfaatan komposit $\mathrm{Fe}_{3} \mathrm{O}_{4}$-zeolit untuk menyerap Mn (II) pada larutan uji cenderung bersifat adsorpsi secara fisika. Menurut T.D Reynold (1982), adsorpsi fisika terjadi akibat adanya perbedaan energi atau gaya tarik bermuatan listrik (gaya Van der Wall's). Molekul adsorbat mulai diikat secara fisik menuju molekul adsorben.Adsorpsi fisika ini terjadi pada zatzat yang bersuhu rendah dengan adsorpsi relatif rendah. Dalam hal ini perubahan panas adsorpsi mempunyai derajat yang sama dengan panas kondensasi dari gas menjadi cair, sehinga gaya yang menahan adsorpsi molekul-molekul fluida biasanya cepat tercapai dan bersifat reversibel, karena kebutuhan energi yang sangat kecil. 


\section{SIMPULAN}

Semakin besar berat komposit yang ditambahkan pada, sampai batas tertentu semakin tinggi penyerapannya terhadap logam Mn. Namun jika titik optimum tercapai penambahan berat komposit tidak lagi signifikan menambah besarnya penyerapan. Pada penelitian ini waktu optimum tercapai penyerapanMn oleh komposit $\mathrm{Fe}_{3} \mathrm{O}_{4}$-zeolit pada kecepatan aduk 100 rpmyaitu 60 menit untuk danberat komposit 0.4 g. Penyerapan $\mathrm{Mn}$ oleh komposit $\mathrm{Fe}_{3} \mathrm{O}_{4}$-zeolit cenderung mengikuti persamaan Langmuir dengan besarnya penyerapan maksimum yaitu $182 \mathrm{mg} \mathrm{Mn}$ untuk $1 \mathrm{~g}$ komposit $\mathrm{Fe}_{3} \mathrm{O}_{4}$-zeolit .

\section{DAFTAR PUSTAKA}

Al-Duri. 1995. "A rivew in Equilibrium in Single and Multicomponent Liquid Adsorption System," Review in Chemical Engineering (11), pp. 101143

ATSDR. 2000. Toxicological profile for Manganese, United state: Departement of Health and Human Sevice, Public Halth sevice Agency for Toxic Substances and Disease Registry.
Dixon, W. SB and J. O. Maloney. 1989. Mineral in Soil Environments second edition, Washington DC : McGrawHill.

Hariani, F. Riyanti and S. Abriyanti. 2014. "Adsorpsi dan Deadsorpsi Zat Warna Metilen Biru Menggunakan Komposit Fe3O4-Zeolit.," in Prosiding Seminar Semirata Bidang MIPA, Bogor.

Levan and G. Carta. 2008. Perry's Chemical Engineer's Handbook 8 th edition, Mc Graw Hill Companies.

Nazaroff and L. A. Cohen. 2001. Environmental Engineering Science, Jhon Willy \& Sons: USA.

Reynold. 1982. Unit Operation and Processes in Environmental Engineering, Montrey: California: Brooks Cole Division.

Sarwanto, G. Tj.S, Mujamilah and G. T. S. 2013. "Identifikasi Fasa Komposit Oksida Besi- Zeolit Alam Hasil Proses Milling," Widya Riset (03), pp. 215218.

Sawyer and P. L. Mc Carty. 1987.Chemistry For Engineering, 3rd ed, New York: Mc Graw- Hill Book Company.

WHO. 2011. Manganese in Drinkin-water, Geneva switzerland: WHO press. 